\title{
Staring at the Sun during Wildfire Season: Knowledge, Uncertainty, and Front-Line Resistance in Disaster Preparation
}

\author{
Alissa Cordner ${ }^{1}$ (D) \\ Accepted: 9 September 2020/ Published online: 16 February 2021 \\ (C) Springer Science+Business Media, LLC, part of Springer Nature 2020
}

\begin{abstract}
As climate change increases the frequency and severity of disasters, and population and social changes raise the public's vulnerability to disaster events, societies face additional risk of multiple disaster events or other hazards occurring simultaneously. Such hazards involve significant uncertainty, which must be translated into concrete plans able to be implemented by disaster workers. Little research has explored how disaster managers incorporate different forms of knowledge and uncertainty into preparations for simultaneous hazards or disaster events, or how front-line disaster workers respond to and implement these plans. In this paper I draw on ethnographic research working as a wildland firefighter, interviews with firefighters and fire managers, and state and agency planning documents to examine preparations for two events occurring in Central Oregon in August 2017: (1) the height of wildfire season and (2) hundreds of thousands of anticipated visitors for a total solar eclipse. I find that different qualities of risk, hazard, and uncertainty across these two events were central to the development and implementation of disaster plans. Agency leaders devised worst-case scenario plans for the eclipse based on uncertain predictions regarding hazards from the eclipse and the occurrence of severe wildfires, aiming to eliminate the potential for unknown hazards. These plans were generally met with skepticism by front-line disaster workers. Despite the uncertainties that dominated eclipse-planning rhetoric, firefighters largely identified risks from the eclipse that were risks they dealt with in their daily work as firefighters. I conclude by discussing implications of these findings for conceptual understandings of disaster planning as well as contemporary concerns about skepticism and conspiracy theories directed at government planning and response to disaster events.
\end{abstract}

Keywords Disasters · Uncertainty $\cdot$ Wildfire $\cdot$ Ethnography

Alissa Cordner

cordneaa@whitman.edu

1 Whitman College, 345 Boyer Ave, Walla Walla, WA 99362, USA 


\section{Introduction}

On August 21, 2017, I sat with several dozen wildland firefighters in a dusty briefing room. It was just after 8 a.m., and we had gathered for our morning briefing on a very unusual day. Two men sitting at the front of the room led us through day's forecast for the hot and dry day along with measures of atmospheric stability and fire risk. Locally, regionally, and nationally, wildfire response was at a "Preparedness Level 5," indicating that fire danger remained high and virtually all available resources, such as fire crews and engines, were already assigned to fires. The daily safety discussion was about the risk management process, and after a crew member read from a printed handout, one of the Assistant Fire Management Officers (AFMOs) for Cascade National Forest, Matthew, asked the attendees, how can we apply that to today? ${ }^{1}$ A firefighter joked, "don't stare at the sun." Today was the solar eclipse.

As the briefing continued about two hours before the moon would completely black out the sun, people described the conditions already on the ground. Karen, an engine captain, said that traffic was backed up on the freeway for miles, with lines of cars pulled over on the side of the road. Matthew told us to "expect some craziness." He continued: "They've talked about impending doom, right, happening for a while." We were all scheduled to work until 8 p.m., but we should prepare for the worst and be ready for a late night if needed.

This day was both typical and atypical of the three fire seasons I spent working with firefighters and fire managers on the Cascade National Forest in the Pacific Northwest. It was the height of fire season during a busy summer: nationally, over 18,000 firefighters were working on 89 large wildfires, including over 300,000 acres of wildfires in the Northwest (NIFC Sit Report 8/21/2017). Several months into an active fire season, firefighters were generally tired but not as exhausted as they would be a month later at the end of the season. Yet the energy of the morning was palpable, as our fire crews and nearly everyone in this part of the state geared up for the total solar eclipse, the first total eclipse to hit the continental United States since 1979. In many ways, the 2017 fire season crescendoed not toward the peak of fire season but toward eclipse day, jokingly called the "eclipse-pocolypse" by the firefighters with whom I worked.

The timing of a total solar eclipse during wildland fire season offers an unusual case study for exploring how disaster managers prepare for multiple or simultaneous hazards. The likelihood and severity of simultaneous disasters is increasing (Mora et al. 2018), yet there is little research on what preparation for multiple hazards or disaster events looks like on the ground. Given the significant uncertainty involved in developing and implementing disaster plans, research is needed to identify how multiple types of knowledge and uncertainty are considered in disaster management, and how front-line workers interact with disaster management plans. In this paper, I draw on my ethnographic research working as a wildland firefighter on the Cascade National Forest to examine how disaster managers and front-line workers - in this case, fire managers and federal agency officials, and on-the-ground firefighters - prepared for and thought about the convergence of two hazards on this National Forest and surrounding areas in August of 2017, (1) the height of a severe wildfire season and (2) hundreds of thousands of anticipated visitors for the total solar eclipse. I ask two related research questions: how do disaster managers develop plans for multiple hazards that involve different forms of knowledge and uncertainty, and how do front-line workers respond to and implement those plans? Merging organizational scholarship on street-level bureaucracy with theories of uncertainty from the sociology of science (Gross 2007; Henderson 2012; Lipsky 1980), I examine how firefighters as front-line responders contend with uncertainty related to 
the likelihoods or hazards associated with disaster events. I draw on ethnographic observations and interviews with firefighters and disaster managers to identify how local and federal agencies developed and implemented their plans for the 2017 eclipse, how those plans overlapped and interfered with preparations for the wildfire season, and how those plans were received, challenged, and implemented on the ground. This research identifies unexpected commonalities in disaster preparations across these two types of hazards and demonstrates the importance of considering forms of knowledge and uncertainty in evaluating disaster preparation, particularly in an era of growing skepticism of public health interventions and intensifying global vulnerability to simultaneous hazards and disasters.

\section{Disaster Management, Risk, and the Front-Line Responder}

This paper focuses on disaster preparation for a severe wildfire season and a total solar eclipse in August 2017. While there is a vibrant interdisciplinary field of hazards and disasters research, the subfield of sociology of disasters has been relatively small and removed from mainstream sociology (Matthewman 2012; Tierney 2007). A shift from the field's focus on natural hazards to the social construction of disaster impacts has allowed for greater attention to long-term, multi-scalar social processes and to issues of power and inequality, vulnerability and resilience, and organizational structure and culture (NRC 2012; Tierney 2019; Wisner et al. 2004). Sociological attention to disasters and their impacts is particularly important as climate change increases the frequency and severity of events such as wildfires (Bachelet et al. 2007).

\section{Disaster Management}

Disasters are generally defined as non-routine events that occur at specific points in time, involve significant harm to people and/or social systems, lead to social disruption, and inspire a collective, social response (Perry 2018; Tierney 2007). Because the impacts of disaster events are socially constructed and depend on the vulnerability of impacted communities (Tierney 2019), understanding disaster planning and preparedness is necessary for understanding the impacts of disaster events. Thus, critical disaster studies distinguish between geological or climatological hazards such as earthquakes, floods, or wildfires, and the socially constructed impacts of those hazards, arguing that "natural disasters do not exist" (Lassa 2016, 1).

Disaster preparedness (or preparation) is one stage in the emergency management cycle, along with mitigation, response, and recovery (NRC 1991). Preparedness involves predicting and preventing disasters and developing plans for before, during, and after disaster events to reduce harmful impacts. A key component of preparedness is a multi-stakeholder planning process to develop common understanding of the hazard, knowledge of capabilities and resources, and set of protocols for reducing risks (Buckle 2007, 500-501). Rather than using different response frameworks for different types of hazards, disaster management increasingly follows an "all hazards" approach, which acknowledges the similar impacts of many seemingly distinct disasters, and thus involves consistent and effective response to any disaster or emergency (DHS 2007). For example, All Hazard Incident Management Teams (AHIMTs) are organized and rostered year-round through the National Incident Management System to respond to all sorts of disasters, ranging from wildland fires to terrorist attacks (FEMA 2019; Miller 2012). ${ }^{2}$ 
While practitioner writing and scholarly research on disaster preparedness is extensive, less is known about preparing and responding to two or more disasters simultaneously (Doan and Shaw 2019), at least in part because these events can rarely be anticipated. Eclipses themselves are not disasters, but they are a type of mass gathering event, defined as an event with enough people in attendance to "strain the planning and response resources of the community, state or nation hosting the event" (WHO 2008, 7). ${ }^{3}$ Eclipses pose potential hazards because the significant number of visitors traveling to see a total solar eclipse has the potential to cause negative impacts and localized social disruption, overwhelm available resources, and inspire a social response. Thus, an eclipse provides a valuable case study for exploring preparation for multiple hazards, since its timing and potential to overlap with other hazard events (such as wildfires) can be anticipated by disaster managers.

Research on multiple disasters that occur in the same place within a defined but longer time period (for example, several extreme weather events in one location over several months or years), cascading disasters in which one triggers the other (for example, mudslides following wildfires), or natech or techna disasters involving the interplay of natural hazards and technological systems (for example, weather events and chemical spills) highlights particular social, economic, and health consequences of experiencing multiple disaster events (Benight 2004; Brunsma and Picou 2008; Cherry et al. 2017; Freudenburg 1997; Gill and Richie 2018; Lyon et al. 2015; Marks et al. 2006 Mills et al. 2019; Moseley 1999; Ray-Bennett 2009). Studying preparedness and planning activities for anticipated events expected to cause significant social disruption, such as a solar eclipse, addresses some of the methodological challenges facing disaster research, since the onset of most disasters can rarely be anticipated (Donner and Diaz 2018). This is particularly the case for "short-fuse" hazards, which occur quickly with little warning (NWS 2020).

Scholars have developed analytical and computational models for multiple hazard preparation and response, for example, modeling pre-positioning and operational allocation of resources to multiple wildfires (Minciardi et al. 2009), or the most effective allocation of resources across multiple cities to simultaneous disasters (Doan and Shaw 2019). However, analytical models provide incomplete information about how disaster managers and front-line responders will actually act during these types of incidents. As scholars note, decision makers may lack analytical training and "rely on experience and simple heuristics" instead of formal models, leading them to "non-optimal decisions" (Doan and Shaw 2019, 701). Similarly, research on organizational response treats "humanness as a limitation" or "an obstacle" (Henderson 2012, 219).

The concept of street-level bureaucracy offers a useful approach for understanding and interpreting the "humanness" of front-line responders (Lipsky 1980). Street-level bureaucrats are public service workers who interact directly with the public and have significant discretion in how they do their work (Lipsky 1980, 3). ${ }^{4}$ While this theory has been widely used to study the work of those in social service, medical, and law enforcement fields (e.g., Henderson 2013; Portillo and Rudes 2014), its relevance for disaster responders has been underexplored (Henderson 2012). Front-line workers actually implement disaster plans and interact with the public before, during, and after events, and thus "the aggregated behavior of individual actors at the front lines of emergency response in essence becomes the response of organizations to critical incidents" (Henderson 2012, 218).

Understanding how street-level bureaucrats do their work requires not only attention to public interaction and discretion, but also an accounting of how front-line workers respond to different types of knowledge and uncertainty. That is, how front-line workers' interpretations 
and evaluations of the knowledge underpinning the policies they are charged with implementing will influence the discretion with which they act and the ways in which they interact with the public. Additionally, the routine and standardization that defines much of street-level bureaucrats' work (Portillo and Rudes 2014) is challenged by unknowns and uncertainties, which are inherently incompatible with routinization. Research has shown that uncertainty related to rules and policies impacts how front-line workers interpret and perform their jobs (Raaphorst 2017). However, for front-line responders, an additional important area of knowledge and uncertainty relates to the definition and understanding of the disaster risk itself. This type of knowledge may be especially relevant in disaster response situations, since identifying something as a disaster or emergency is "organizationally and situationally developed" (Lipsky 1980, 137). Little is known about how front-line workers or other stakeholders, including skeptical publics, mobilize "resistance against risk management policies" (Hagen 2019, 1235). Qualitative and observational research can provide useful information about how plans are developed, implemented, and questioned by decision makers and disaster workers in real-time situations.

\section{Uncertainty and Risk in Disaster Management}

Disaster preparedness aims to reduce the risks from disaster events to impacted populations. Disaster risk can be conceived of as involving four components: hazard (how dangerous something is and what the dangers are), likelihood or exposure (how likely the hazard is to occur), the vulnerability of those impacted, and some evaluation of uncertainties (Tierney 2007; Wisner et al. 2004; Zinn 2008). Disaster risks are socially determined, rather than being solely determined by the physical, geological, or climatic hazard, meaning that the impacts depend greatly on the vulnerability of potentially impacted populations and how social institutions organize themselves ahead of, during, and after the disaster (Tierney 2007). Uncertainty is inherent in the concept of risk (Luhmann 1995), both because risks refer to "future, unrealized threats which can only be partially predicted" and because "the scope and scale of hazards and likelihoods is never fully known" (Cordner in press). Sociologists have long demonstrated that organizational form and culture can both directly contribute to catastrophic events and to inaccurate or incomplete assessments of risk (Clarke 1989; Paté-Cornell 1990; Perrow 1984; Vaughan 1999). For example, Vaughan found that mistakes related to the Challenger space shuttle explosion were "socially organized and systematically produced" by an organizational culture that normalized deviance from safety requirements (1996, xiv).

Uncertainties related to disaster events create challenges for disaster preparedness. Extremely rare or unprecedented "black swan" events evade accurate risk characterization because they "have never been encountered before (to the best of the observer's knowledge) and in principle, cannot be anticipated" (Paté-Cornell 2012, 1824). As Cerulo (2006) notes, stakeholders frequently claim that severe disasters could not be anticipated. Yet disaster management is devoted to the prediction and management of hazards and their impacts. The anticipation of worst-case scenarios lends itself to what Clarke (2006) terms "possibilistic" thinking, where even low-probability events inspire a collective response. However, more information does not inevitably lead to more complete risk characterization. As Gross (2007) notes, ignorance and knowledge exist in a "dynamic and recursive" relationship (742). Rather, "knowledge about the limits of knowledge," his definition of ignorance, "increases with every state of new knowledge" (Gross 2007, 751). Knowledge about disaster events typically involves estimation and interpretation, and thus depends on individual and collective social 
factors (Eiser et al. 2012). Because knowledge about disasters is socially produced, relevant uncertainties are not merely derived from the absence of information but also include gaps due to historical knowledge and data collection; reliance on particular instruments, heuristics, or theories; and the use and measurement of particular interventions (Neale and Weir 2015).

In disaster management, uncertainty is not simply the absence of information, but rather involves a complex interplay of multiple forms of knowledge and ignorance (Gross 2007; Kerwin 1993). When emergency managers and institutions plan and prepare for disaster events, they are confronted with different forms and levels of knowledge related to the hazards associated with the disaster and the likelihood it will occur in a specific place and time (Table 1). ${ }^{5}$ Known knowns are areas of knowledge involving a clear, accepted understanding of hazard or likelihood, referencing a source of knowledge deemed sufficient by the group in question (Gross 2007; Kerwin 1993), and include clearly understood hazards and precisely predicable occurrences of disaster events. ${ }^{6}$ The source of this knowledge may be expertderived: disaster managers "know" when and where an eclipse will occur based on calculations and interpretations from astronomers, physicists, and geographers. The source of knowledge may also be experiential: firefighters "know" that wildfire likelihood increases under certain conditions based on their accumulated individual and collective experience. Known unknowns (what Gross calls non-knowledge) involve a clear, accepted understanding about what is not known "while taking it into account for future planning" (Gross 2007, 751). In the case of known unknowns (or non-knowledge), a disaster's hazards or likelihoods are estimated or extrapolated from prior events, places, or other sources of data, and the assumptions and limitations of these estimation practices are acknowledged and considered in evaluating the hazards and likelihoods. A type of known unknown called extended knowledge involves explicitly taking non-knowledge into account in planning or research processes (Gross 2007). Finally, unknown unknowns (what Gross calls nescience) refer to a complete "lack of knowledge" (Gross 2007, 751). No prior data or experience allows for the accurate estimation or prediction of hazards or likelihoods, putting disaster managers into potential situations of "total surprise" (Gross 2007, 751). Black swan events would fall into the unknown unknown category (Aven 2013; Paté-Cornell 2012) because by definition they cannot be anticipated with present knowledge.

Table 1 Uncertainty and Risk of Disaster and Mass Gathering Events

\begin{tabular}{|c|c|c|c|}
\hline & & Hazards & Likelihood \\
\hline \multirow[t]{2}{*}{ More Certainty } & Known Knowns & $\begin{array}{l}\text { Hazards are clearly understood } \\
\text { based on prior experience with } \\
\text { similar events; Comprehensive } \\
\text { models, plans, and practices } \\
\text { exist }\end{array}$ & $\begin{array}{l}\text { The likelihood of the event } \\
\text { occurring at a particular time } \\
\text { and place is concretely known }\end{array}$ \\
\hline & Known Unknowns & $\begin{array}{l}\text { Hazards are extrapolated from } \\
\text { other hazards and/or scenarios; } \\
\text { Potential gaps and implications } \\
\text { of those extrapolations are ac- } \\
\text { knowledged and considered in } \\
\text { planning }\end{array}$ & $\begin{array}{l}\text { The likelihood of an event } \\
\text { occurring at a particular time } \\
\text { and place is evaluated } \\
\text { probabilistically or otherwise } \\
\text { estimated; Potential gaps and } \\
\text { implications of those } \\
\text { extrapolations are } \\
\text { acknowledged and considered } \\
\text { in planning }\end{array}$ \\
\hline Less Certainty & Unknown Unknowns & $\begin{array}{l}\text { Hazards are unknown and cannot } \\
\text { be accurately predicted or } \\
\text { envisioned; Includes black swan } \\
\text { events that cannot be anticipated }\end{array}$ & $\begin{array}{l}\text { No prior data or experience exists } \\
\text { on the likelihood of the event } \\
\text { so it cannot be accurately } \\
\text { estimated }\end{array}$ \\
\hline
\end{tabular}


Focusing on preparedness for two anticipated events (the solar eclipse and a severe wildfire season) allows for an examination of how emergency managers plan for multiple hazards, identifying and considering the different types of uncertainty with which those managers are faced, and how those plans are evaluated and implemented on the ground. In the case of wildfires in Central Oregon in late August, fire managers have a reasonable expectation that wildfires will happen somewhere in the region sometime in August, but they do not know the specifics of when, where, or what will take place. Thus, managers have a relative degree of certainty related to the hazard but do not know the exact likelihood (Fig. 1). In contrast, an eclipse is an unusual type of event because disaster managers know exactly when and where the eclipse disaster will take place, but they do not know exactly what the social and environmental impacts will be: they know the likelihood with a high degree of certainty but have less certain information about the hazard. Preparations for these simultaneous events involve balancing one against the other. For example, improved preparation for the eclipse could mean limiting initial attack operations on new wildfires so that more resources are available to help with eclipse response, but this would increase the risks of local and regional wildfires growing beyond the initial attack phase and requiring a more significant mobilization.

\section{Eclipses and Wildfires}

Following the all hazards approach to emergency management described above (DHS 2007), the 2017 eclipse was treated as a potential catastrophic event by local emergency managers. (Of course, managers also saw the eclipse as a recreational and scientific event, and a potential once-in-a-lifetime personal experience.) As mentioned above, eclipses can be thought of as mass gathering events (WHO 2008). Mass gathering events include major sporting events (e.g., Olympics), entertainment activities (e.g., music festivals), or religious or cultural

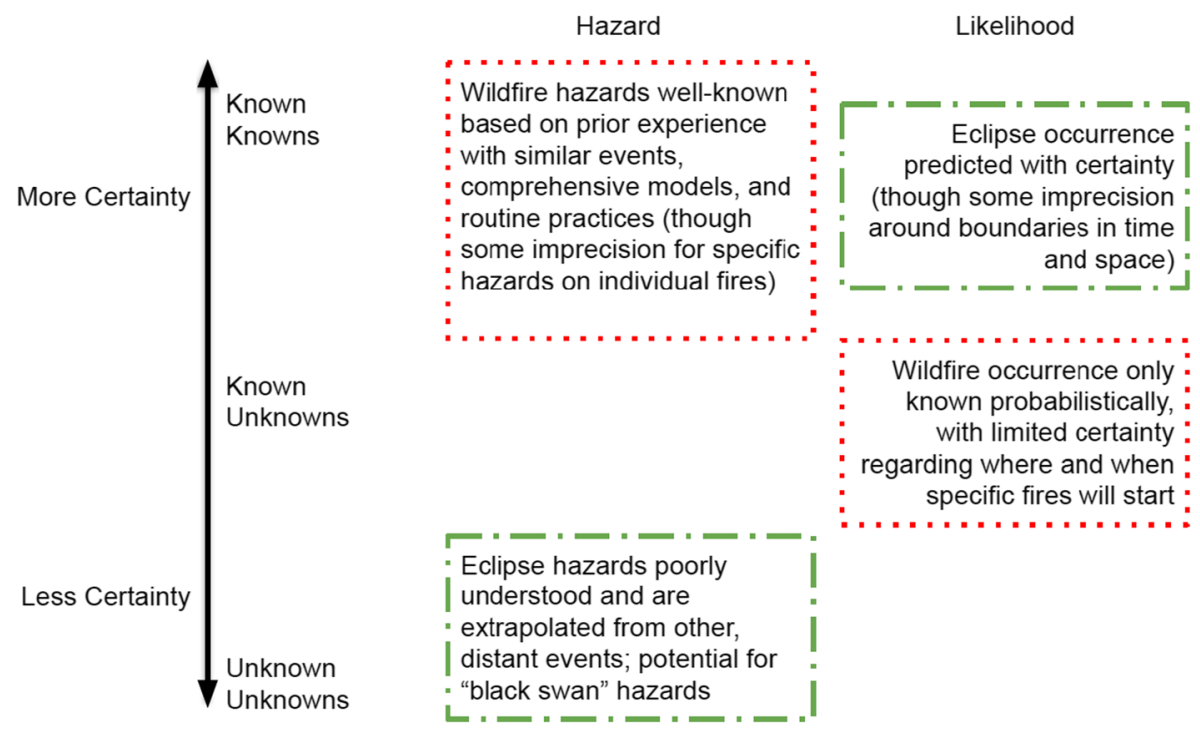

Fig. 1 Relationship between Uncertainty, Knowledge, and Risk 
activities (e.g., religious pilgrimage). The timing and location of most mass gathering events is typically known well ahead of time and thus impacted communities and stakeholders can develop preparedness and response plans. ${ }^{7}$ Research and planning related to mass gathering events typically focuses on "preventing, minimizing and responding to public health emergencies" (WHO 2008, 14) by providing medical services and responding to public health incidents such as communicable disease outbreaks (Soomaroo and Murray 2012). I found no research in the social science or disasters literatures on eclipse preparations.

Despite their significant impacts on property, infrastructure, health, and injury and loss of life, the social aspects of wildfires have received less scholarly attention than hazards such as earthquakes and hurricanes (Paveglio et al. 2011). However, a growing body of social science research on wildfires has focused on issues including community wildfire preparedness, manager interactions with local communities, public perception and support of wildfire policies and prescribed fire, public response during fires, and recovery, among other topics (Brenkert-Smith 2013; Meldrum et al. 2018; McCaffrey 2015; McCaffrey et al. 2013). In recent years, wildland fires in the United States have grown in total number of acres burned and in measures of destructiveness (National Interagency Fire Center 2019). Anthropogenic global climate change contributes to higher temperatures, record droughts, stronger winds, and reduced snow packs (Bachelet et al. 2007), leading to drier fuels, less water available for suppression, and a longer wildfire season. Additionally, risks to people have increased as more people live in the wildland-urban interface (WUI), places where developed settlements abut or are intermixed with forest or brush lands. In the United States, over 120 million people live on 220 million acres of WUI (International Association of Wildland Fire 2013). Agencies and managers prepare for wildfire season and specific events using many strategies and procedures, including training and resource development, anticipating resource shortages, and prepositioning resources and people. Immediately preceding and during an event, they can also use regulatory interventions (e.g., area closures or fire bans) and enforcement tactics (e.g., increase patrols by law enforcement officers) to reduce risks from expected events.

\section{The Case}

\section{Wildland Fire Management in Central Oregon}

This paper draws on ethnographic research conducted with the wildland fire management organization of Cascade National Forest in Central Oregon. ${ }^{8}$ The general area of Cascade National Forest includes several small cities ( $<100,000$ residents), numerous small towns, extensive outdoor recreation opportunities, and agricultural and timber communities. Wildfire operations on land managed by the US Forest Service (USFS) and Bureau of Land Management (BLM) are managed collaboratively through an Interagency Fire Management Service (IFMS). Also located in the region are national-level wildfire resources that can be dispatched to non-local fires, including smokejumpers, rappellers, and hotshot crews. ${ }^{9}$ The IFMS district in which I worked staffed two handcrews and roughly six engines every day during the summer with full-time firefighters who were a mix of seasonal and year-round employees. ${ }^{10}$ Firefighters worked a minimum of $40 \mathrm{~h}$ a week, and overtime was common and expected during periods of high fire risk. ${ }^{11}$

Risk management policies and plans are developed at high levels within agency bureaucracies, while the implementation of those plans falls to on-the-ground individuals much lower 
in organizational hierarchies. The fire management hierarchy in the IFMS with which I worked is summarized in Fig. 2.12 Office-based leadership develop the plans and procedures, and spend their days largely in the office. High ranking "agency administrators," including forest superintendents or district rangers, do not necessarily have experience as wildland firefighters, though they would have some training in fire organization and operations. The "office overhead," who come from a firefighting background, typically spend little time at this point in their careers working boots-on-the ground in firefighting roles, though most are members of AHIMTs and are dispatched to large fires several times per season in leadership roles. The fire operations staff, on the other hand, are based in the field. "Field overhead," fire operations leadership with decades of experience, go into the field on a regular basis, though they are rarely swinging tools themselves. "Field operations"-crew members, squad bosses, and captains - are in the field every day engaged in physical labor as firefighters.

Central Oregon is an ideal location for investigating wildland fire management. Cascade County ranges from developed agricultural land and high desert areas, to mature pine forests at the base of 9,000-ft mountains. The Cascade National Forest includes land in multiple predominantly rural counties. The region experiences significant, and varied, fire activity each year. In a typical summer, the area will see several hundred wildfire starts, the vast majority of which are fully suppressed during "initial attack," the first efforts to put a fire out the day or day after it is reported. The region also has a history of large fires that have destroyed homes and forced evacuations in and around the area's population centers.

In addition to an interesting fire regime, Central Oregon is an ideal location for studying wildfire risk management because of the variety of communities and residents living in close proximity to federal and state forest land. Some areas are populated with affluent amenity seekers living in Central Oregon for close access to recreational opportunities in the mountains and cultural resources related to a vibrant brewery and cultural scene in and around the largest city of Forestville. However, many areas of Central Oregon are low-income and decidedly rural. Examples of all four types of WUI communities identified by Paviglio and colleagues (2015) can be found in Central Oregon. This diversity suggests that forest and fire management decisions, forms of community involvement, and types and levels of community resources will vary significantly across the region.

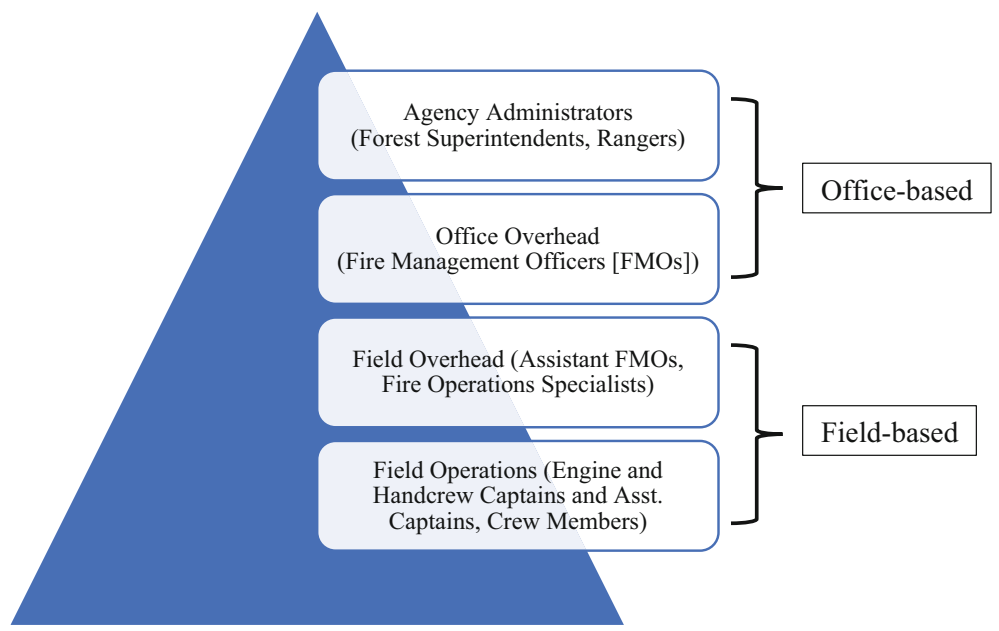

Fig. 2 Simplified Wildfire Management Hierarchy 


\section{Solar Eclipse}

Total solar eclipses occur when the moon travels directly in front of the sun during the day. The sun is 400 times wider than the moon but the sun can be blocked completely because the moon is 400 times closer to the earth (NASA 2017a). Prior to the 2017 eclipse, the last total solar eclipse in the contiguous United States was in 1979, and the next will occur in 2023.

Parts of Central Oregon were within the "path of totality," the area where the sun is completely blocked by the moon, allowing for several minutes of surreal darkness. The State of Oregon predicted that as many as 1 million people could travel to Oregon for the eclipse, and Central Oregon alone was told to expect 200,000 visitors, more than the total population of the region (McLaughlin 2017; Spurr 2017). Given the region's typical weather and low levels of light pollution, Central Oregon was identified as one the best places for viewing. NASA observed the eclipse in Madras, Oregon, two and a half hours southwest of Portland (NASA 2017b). A "modern-day neo-hippy festival" held at a large ranch east of the 10,000-person town of Prineville, Oregon hosted more than 30,000 ticket-buying attendees (Scruggs 2017), leading to a 14-mile traffic jam the day before the eclipse (Spurr 2017).

\section{Methods}

I conducted participant observation with fire managers and firefighters in the Cascade National Forest for three fire seasons $(2015,2016$, and 2017) (IRB approval from Whitman College). I completed the initial training program required of new wildland firefighters, along with required annual physical fitness tests and refresher trainings, and am "Red Carded" as a Firefighter Type 2, the lowest level of certified wildland firefighter. For these three fire seasons, I worked as a wildland firefighter on handcrews and engines, shadowed various fire personnel on local fires and prevention activities, took additional training courses, and traveled with an AHIMT on regional fire assignments. Additionally, I observed and gathered material from various community meetings and events related to wildfires, and conducted semistructured qualitative interviews with firefighters, fire managers, and other fire experts.

Throughout my ethnographic research, I explained my role as a researcher studying the social and political aspects of wildfire risk management, and requested permission from individuals and crews to shadow their work, and from supervisors to participate in training programs and activities. I explained to all individuals with whom I worked that I would only use pseudonyms to protect confidentiality. To take fieldnotes, I carried a small notepad in the bulky cargo pockets of my firefighting pants and took jottings in the moment, including verbatim quotations when possible (Emerson et al. 2011). I typed up detailed fieldnotes as soon as possible after my fieldwork concluded, typically that evening or the following day, retaining any verbatim quotations from my field-based jottings. To be as accurate as possible in how I present my data, quotations are marked with "double quotes" when they are verbatim quotations from my field jottings or interview transcripts and 'single quotes' when they are passages taken directly from my typed fieldnotes.

This paper mainly utilizes data from the 2017 fire season, though my analysis is informed by all three years of research. From early June to mid-August 2017, I spent 31 field days working as a wildland firefighter on an engine or handcrew, with daily field time ranging from 9 to $24 \mathrm{~h}$. This included working as a crew member on a wildland fire engine every day the week of the eclipse. Most of my participant observation research was conducted on a fire 
district that experienced $99 \%$ totality during the solar eclipse, so local impacts were somewhat less than parts of the state that experienced $100 \%$ totality. I also attended training and leadership meetings that included eclipse-specific discussions and planning activities. I had countless conversations with people about the eclipse over the course of the summer and documented these in my fieldnotes. I also gathered documents related to the eclipse, including planning documents distributed at meetings and shared with me by fire managers.

To supplement my observations and identify specific patterns related to how firefighters thought about the eclipse, I conducted focused interviews with 17 firefighters, ranging from first-year crew members to fire managers with over 25 years of experience. In these interviews, I asked about their expectations for the eclipse and their thoughts on the biggest eclipse-related risks posed to firefighters and the general public. The majority of these interviews took place in group settings, typically interviewing all members of a single crew (e.g., three people working on the same engine). These group interviews had both strengths and limitations: while interactions between crew members brought out additional ideas and richer elaborations, some quieter crew members spoke less than they might have in a one-on-one interaction. I transcribed interview recordings verbatim. Three individuals declined to be recorded, and so I took detailed notes and typed them up soon after.

I analyzed fieldnotes and interview transcripts in NVivo 12, a computer program that manages qualitative data. Following Ragin and Amaroso's (2019) interpretive model of research, my analysis moved iteratively between my data and theoretically informed analytic frames. I began with an initial list of themes and topics derived from my research questions and prior research, focused on the process of preparedness and risk perception. I revised and added to my coding structure through preliminary reading of fieldnotes and interview transcripts, adding codes related to skepticism, interactions between levels of authority, and changing perception. This paper reports on themes and patterns related to the eclipse that emerged from this coding process.

To supplement my understanding of community and agency preparations for the eclipse, particularly public events that occurred outside of my fieldwork window, I also read local newspaper and social media coverage of eclipse preparations and response. I gathered newspaper articles by searching for "eclipse" in articles from January through September 2017 in four state, regional, and local newspapers (unnamed to protect the identity of my research location). I also gathered Facebook posts from January through September 2017 related to the eclipse from the local USFS office, BLM office, and Cascade County Emergency Management. I do not always directly cite relevant news articles or social media posts if doing so would identify people or places in my research.

\section{Findings}

The 2017 eclipse was seen by all as a unique experience, though what was noteworthy for firefighters and fire managers were the potential hazards and chaos associated with the huge influx of visitors, not the eclipse itself. As Jed, an engine captain, told me, "I mean, for my career, I'm never, never gonna have an experience like what's going to happen, I guess, if their predictions are right." Early season predictions for the 2017 fire season were not particularly extreme due to a wet winter and above-average snowpack (NRCS 2017). However, an unusually hot and dry summer quickly depleted snow reserves and dried the fine grasses that flourished in the wet spring, leading to severe fire conditions (Guevarra 2017). By August, the 
Northwest region's wildfire risk was at a National Preparedness Level 4 (out of 5), as eight large fires burned in Oregon and Washington (NWCG Sit Report 8/01/2017). Ten days later, the National and Regional Preparedness Levels were both at 5, indicating that virtually all available resources in the Northwest and nationally were assigned to active fires (NIFC Sit Report 8/11/2017). This wildfire season provided the backdrop for eclipse planning and response.

\section{Preparing for the Worst}

Dedicated eclipse preparations by federal, state, county, and local agencies began a full year ahead of time and were in full swing by early 2017. ${ }^{13}$ A planning spreadsheet for part of the Cascade National Forest indicating timelines and "due dates" included two items for summer of 2016 and seven action items for January 2017. Their preparations involved extended knowledge (Gross 2007) from two main sources: previous eclipses in other parts of the world and previous large gatherings in the region. USFS managers queried their counterparts in other parts of the country and world who had experienced eclipses in the past, since Central Oregon had not experienced a total solar eclipse in over a century (Time and Date 2019). They also drew on their experiences with other large influxes of visitors, notably "Rainbow Family of Loving Light" festivals (also called Rainbow gatherings) that bring tens of thousands of visitors to National Forest lands every summer (Rainbow Family 2018). The Rainbow gatherings have a troubled relationship with the USFS, since organizers refuse to seek the permits required for such a large event. Concerns related to past Rainbow gatherings in Oregon and elsewhere include impact to public lands, limited access to sanitation facilities and safe drinking water, interpersonal violence, drug use, and infectious disease outbreaks (CDC 2000; Hamway 2017a; Pillai et al. 2010).

Eclipse preparations were grounded in a combination of known knowns, known unknowns, and unknown unknowns (Fig. 2). Some things were clearly known: the date and time of the eclipse, and the astronomically-determined path of totality. Other topics blurred the line between certainty and uncertainty: the number of visitors, where they would be, how long they would stay, and what their impacts might be. Local and state emergency managers took as fact that the crowds would be substantial while acknowledging significant uncertainty regarding visitors' plans: they knew it would be bad, they just didn't know how bad it would be. This uncertainty was reflected in contemporaneous media coverage. A newspaper article in February quoted a Forest Service public affairs officer laughing at the idea of visiting the region during the eclipse for any other reason: "If you don't care about the eclipse, don't come at that time... Everything is booked; we already know there will be traffic issues and problems with resources in general" (Madsen 2017). Early predictions also linked eclipse traffic with wildfire risk. As the emergency manager for another Central Oregon county told a reporter, "If we're going to have a big fire, we're going to have it that week" (Hamway 2017b). Yet while some aspects of the eclipse were described with relative certainty - the crowds of visitors and the heightened risk of traffic problems and wildfires - forest managers also emphasized uncertainty: "This is not an event we can get a list of RSVPs for," said a BLM spokesperson (Hamway 2017b).

Preparations throughout the spring were collaborative and multi-agency, involving office overhead and agency administrators. In April of 2017, Cascade County convened an eclipse planning group for a day-long interagency simulation of emergencies that could arise on eclipse day, including a stranded hiker, major car crash, a medical incident, and a wildfire. 
More than 85 attendees came from a dozen agencies, including USFS, BLM, and the Oregon Department of Forestry, along with the Oregon Department of Transportation (ODOT), local fire departments, and County emergency Management departments. Throughout the spring and early summer, planning operations continued within the wildfire operations system. Regularly scheduled meetings, such as the district's weekly fire leadership meeting, added the eclipse as a standing agenda item. The USFS developed detailed written plans for numerous aspects of the eclipse, covering topics ranging from staffing extra wilderness rangers in peak viewing locations to plans for extra porta-potties and garbage collection. Fire managers were actively working to move eclipse hazards from the uncomfortable territory of the unknown unknown to the more familiar space of known unknowns by trying to "think of everything."

I observed the ubiquity of eclipse preparations starting on my first day returning to fieldwork in 2017, at an all-day training in late May for Incident Commanders of Type 4 and 5 fires, wildfires that are generally small and low in complexity and risk. Over one hundred people gathered at a county fairground in a high-ceilinged building filled with rows of folding chairs. After a couple of brief welcome messages from agency administrators, the training turned to the eclipse. Two office overheads, Allen and Barry, talked about planning for the eclipse and for a (relatively) smaller gathering of the Rainbow Family that was expected to take place in July and blend into the eclipse celebrations in August. Barry said that the eclipse will be big: "we don't know exactly how big, but estimates range from 100,000 to 500,000." The eclipse would travel across the whole country, he explained, 'but according to meteorologists, the Northwest has the best potential for clear skies.'

Barry ran through expected problems around the time of the eclipse: major resource shortages, no hotel rooms available for out of town firefighters, impacts on travel routes, and damage to public lands: 'it may be hard to respond and it will be hard for resources to travel to or across the eclipse route.' Allen added, 'there may not be cell service, just like if you're in a stadium and you can't get service because it overwhelms the cell towers. [Also] there won't be fuel or resupply.' They had already reserved a local middle school and fairgrounds, planning to use the two facilities for wildfire operations and a public information center. Allen suggested they might move aircraft out of Central Oregon entirely because airspace would be too busy, and firefighters might be diverted to vehicle accidents or Search and Rescue operations.

Allen and Barry, high-ranking office overhead who had been extensively involved in eclipse planning all year, highlighted the known unknowns related to the eclipse: areas in which they were sure of their ignorance but were nonetheless developing plans. Allen noted that the eclipse creates lots of work, on top of the middle of fire season. Barry agreed: according to the Northwest Coordinating Center, which tracks wildfire statistics and resources, on average the region has four or five large wildfire incidents in mid-August and three or four emerging incidents. Allen described the eclipse as 'an unusual incident because we know when it's happening.' They could pin down the likelihood at a specific point in time: the eclipse will take place on August 21. But they had to make their best-informed predictions about what the hazards would be.

Developing knowledge of those hazards took fire managers in unusual directions. On a warm July day, I met with Mark, a district ranger for the Cascade National Forest. He had come to the morning briefing at the fire compound to talk to all the firefighters about the eclipse, and I stayed after to talk with him. He said, 'they are thinking of everything' and doing 'really high-level planning.' Someone had calculated that with the additional visitors in the 
region, they could see up to 14 deaths per day, twice the typical number, which would overwhelm the local morgue: "somebody thought to look at the space in the morgue," he said, smiling and shaking his head.

As another example of the constancy of eclipse preparations, I met with Stuart, another District Ranger, in his office. On the wall behind his desk, he had a day-by-day countdown to the eclipse along the lines of, "days till all hell breaks loose." He told me I was his break from a long eclipse meeting: 'It feels like all they're thinking and talking about,' and he was glad for the change in pace to talk about a recent wildfire.

\section{Known Knowns and Known Unknowns}

The likelihood of the eclipse was known: it would occur in the late morning on August 21st. But significant uncertainty surrounded the types and severity of different hazards. An official briefing document for non-emergency USFS preparations highlighted numerous "potential impacts," including traffic, shortages of supplies like gasoline, overwhelmed communication systems, and increased demand for response to non-fire emergencies like traffic accidents and medical incidents.

In interviews the month before the eclipse, firefighters generally emphasized two general hazards from the eclipse: driving and public behavior. Many firefighters mentioned driving as a major risk both to them and, to a lesser extent, to the public. Evan, a sixth-year firefighter in his thirties, connected eclipse-specific risks to the dangers of his job generally: driving, he said, "that's our biggest hazard. That's how most people get killed on the job, is driving." Others noted that the volume of traffic would delay response to other emergencies, including wildfires, and could make it difficult for them to do their jobs. As Nathan, a member of the field overhead team with over 20 years of fire experience, explained,

Driving is going to be the biggest risk, you know, getting people to a fire and back home from a fire is the biggest risk. We're all very good at our jobs. We've pounded in the safety thing with hazards and snags all summer long, and we've been really good at that. It's just the driving aspect. A lot of crazy people from outside the area, not knowing how to drive through roundabouts, blowing red lights, blowing stop signs, people getting lost in the woods. I think that's going to be the biggest hazard to the firefighters.

Driving risks are familiar to firefighters. In addition to dedicated classes needed before driving any agency vehicle or the training for a Commercial Drivers License required to operate the heavy engines, the dangers of driving are reiterated in multiple ways throughout a firefighter's career. This includes annual "Red Card refresher" recertification trainings and regular mentions in the "Six Minutes for Safety" covered at the start of every morning briefing (NWCG 2020).

Firefighters also pointed to risky public behaviors ranging from drug and alcohol use to mob behaviors, what they casually referred to as "shenanigans" or "stupid human tricks." Several firefighters predicted extensive drug use on national forest land and that they would see increased numbers of overdoses and suicides. Susan, a handcrew squad boss, said that public interaction could be a risk to firefighters: "public contact, especially for people who are out doing something wrong, it's kind of like a risky thing for us... We're not law enforcement, we don't have guns, we don't have anything to really, like, protect us. So that's kind of risky." Nathan echoed this concern, especially for fire people who traveled solo, such as Prevention and Fuels Technicians: "there's going to be an influx of crazy people, probably hopped up on 
drugs and marijuana and everything, the confrontation that they could have, that poses a, to me, a big risk to our firefighters."

In interviews, few firefighters specifically linked eclipse-related risks to wildfires. Joey, an assistant engine captain, said that his biggest concern was firefighters being put in situations they weren't prepared or trained for, especially first- or second-year firefighters "without any experience other than trees and dirt." Daniel, a first-year firefighter on an engine, and William, a squad boss-level firefighter on the handcrew, both named escaped campfires as a major risk. Yet overall there was little expressed concern that eclipse risks would morph into wildfire risks.

\section{Tempered Expectations and Changing Plans}

Operational plans for what firefighters would do during the eclipse period were developed by individuals (nearly all of them men) in field- and office-based leadership positions, in meetings and in agency offices. Individuals falling in the "Field overhead" category (Fig. 2) involved in eclipse planning drew on their own experience working in the field, took the pulse of firefighters, and developed and revised plans accordingly. However, people in field operations positions had no direct lines of input into the eclipse planning process; no crew members or even captains sat on eclipse planning committees. After plans were partly or fully developed, they were shared at morning briefings at the fire district compound, which were attended by field overhead, firefighters, and visitors such as agency administrators or firefighters from Forestville Fire or other nearby agencies.

In early August at one of these meetings, we sat in the fire compound's dusty briefing room. Field overhead who had been involved in eclipse preparations shared preliminary plans for the eclipse Incident Action Plan, a document that would guide operations for the week of the eclipse. Phil, an AFMO, said everyone would likely be on 12-hour shifts, 08:00 to 20:00, the week leading up to the eclipse, with an earlier morning on eclipse day. Two engines would be stationed in Forestville, positioned close to the highway for quick response to nearby incidents. The two handcrews and four other engines would be prepositioned at field sites around the district, and those crew members would camp overnight from Friday through Tuesday, the day after the eclipse. Kevin, an engine captain, asked, 'if we are only being paid for 12 hours, can we leave? Or you should increase our hours to 16,' the standard "full" day at fire camps of large incidents. Another captain agreed and added they should also be receiving field perdiems if they have to stay in the field.

This represents a rare moment of the field pushing back and possibly directly influencing the eclipse plans. Kevin doubted the necessity of plans based on uncertain assessments of the eclipse's impacts, and asked for modifications to improve the working conditions of front-line workers. This message was heard by some field overhead. When I spoke to Nathan, he said he agreed with not "stashing people" at distant guard stations. However, he wasn't part of the eclipse planning team: “They're set on [certain locations], so I'm just kind of letting Phil and Matthew do their thing and I'm just here to support them." Respect for the organizational hierarchy that defines the wildland fire service (Desmond 2007) remained firmly in place.

The closer we got to eclipse day, the more skeptical firefighters became of the crowds and chaos predicted earlier in the summer. Forestville was relatively quiet, and newspaper articles and social media posts noted that the promised throngs of customers had not arrived at local businesses. Fuel prices increased and a few stations ran out of gas or diesel, but only temporarily. Five days before the eclipse, I spent the day on an engine with two firefighters, 
each with at least five years of experience. Joey, an assistant engine captain in charge of the engine for the day, commented as we drove out of town that it was "ridiculously calm and dead here." He had talked to his wife that morning as she shopped at a big box store, and she said 'it was empty.' Joey added, 'I bet it's busy north [in the path of totality]. If people are coming all this way for the eclipse, they're going to be right in the thick of it.'

Several days before the eclipse, leadership scrapped the plan to station firefighters at distant guard stations but left in place a 6:30 a.m. start time. The morning before the eclipse at briefing, Chris, another field overhead, emphasized the quality of preparation: 'we have a lot of resources. We've prepared a lot... we're ready.' He noted that even though they had likely overprepared, 'we can still get stripped down pretty quickly,' particularly with growing fires in and around the Cascade National Forest. Matthew nodded, adding that they were revisiting the 6:30 a.m. start time for tomorrow. By evening, when we all returned to the fire compound from a day patrolling and responding to fires, the start time for eclipse morning had changed to 8 a.m.

\section{Skepticism: Just like Y2K}

Among field operations firefighters, opinions abounded that the approach was overkill. Even Mark, the District Ranger, mentioned this after discussing morgue preparations: 'they are preparing for the worst,' but he thinks it's a 'possible overreaction.' He told me hoped it would turn out like $\mathrm{Y} 2 \mathrm{~K}$, a coding problem that led to fears that computers would stop working when the date switched from 1999 to 2000 . Y2K was a common metaphor for the eclipse. In a group interview with three engine crew members, Rusty, the assistant engine captain, proclaimed, "It's going to be like Y2K." He looked at Travis, who in his mid-twenties was the youngest on this engine. Rusty explained, laughing, "you're too young! Where everyone's going to panic and nothing's going to happen." Travis smiled and affirmed his youth: "I was six." The engine captain, Kai, agreed: "most of it's hype."

Several firefighters told me it could be all or nothing. Mike, a first-year handcrew member, said, "it's going to be a cluster-... or it's like, they've hyped it up so much it's, it might feel underwhelming." Brian, another first-year firefighter on a different engine, offered a similar assessment: "it's being billed as the apocalypse, but, I mean, I'm trying to go into it with zero expectations because I honestly think it's gonna be, like, it's either gonna be the shitshow that everybody expects or it's going to be a fraction of that." Jed, an engine captain who had worked in fire for over 15 years, stated: "I don't think it's going to be as end-of-the-world as people are predicting." Another member of his crew concurred: "I think there might be a slight increase in traffic and a little bit of stuff like that, but I don't think it's going to be all, you know, all hell breaks loose... It's not going to be, like, chaos or anything."

The morning of the eclipse itself, firefighters gathered at $8 \mathrm{a} . \mathrm{m}$. at the fire compound. The district staffed seven full engines. This was more than would be typical for the height of fire season: because of the eclipse, fewer firefighters had been permitted to go to fires off-district, and several engines were partially staffed agency "militia," people working non-fire departments (like recreation, timber, or trail maintenance) who filled in on fire assignments. Unlike most mornings, when almost everyone exercised right after briefing and thus wore running clothes to the meeting, everyone was neatly dressed in green Nomex pants, dark blue district tshirts, and laced fire boots. AFMO Matthew led the group through a brief risk management discussion and warned of the possibility of "impending doom" and "craziness" out in the field. He noted that traffic was already backed up on the major highway cutting through town and 
some cars had pulled off to the side of the highway to watch, disobeying instructions from ODOT.

Toward the end of briefing, Nathan talked about the Lynx Fire, which was burning roughly 25,000 acres west of a nearby town. He said that several task forces of engines had just been pulled off the Lynx Fire and reassigned to a major fire elsewhere in the Northwest, 'so if things start burning to houses there, we'll stand up our task force. So be ready.' Right after briefing, everyone grabbed water bottles and lunch bags, and headed to their trucks. The engine I was assigned to for the day was part of that task force that would be dispatched to the Lynx Fire if needed, and the first topic of conversation in the engine wasn't the eclipse we were about to see, but whether we would be dispatched: "they dangled the carrot again," said Rusty, referring to the possibility of being dispatched to the active wildfire.

Despite the nearby wildfire, we had a clear view of the mountains as we drove out of town to our viewing location. We had all been given sets of eclipse-viewing glasses, and we sat on top of the fire engine to watch the moon slip in front of the sun. As we headed back to Forestville after the eclipse, we waited for several minutes before we could pull onto the main road, watching as a solid line of cars drove past. Kayla said, "this is what they warned us about."

We spent the rest of the morning at the fire compound, cleaning and organizing equipment, and after lunch headed to a campground west of town, a common spot to stage in case any fires were reported. Driving out, we could see the smoke column from the Lynx Fire, and talk again turned to why no engines from our district - especially our engine - had been called to help with the fire. The only wildfire call we had that day was a smoldering campfire in a dispersed campground area, lit in spite of fire restrictions, which we quickly dug into the dirt. Other engines and the handcrews had similarly quiet days. Beyond the fire district, the worst expected impacts of the eclipse did not materialize. There were localized traffic headaches and some isolated fuel shortages, but Forestville did not need to use its back-up morgue and the fire district did not mobilize for eclipse-related wildfires. According to Oregon's Office of Emergency Management, "State emergency managers received no reports of eclipse-related deaths or injuries... [and] no human-caused wildfires started in the path of totality" (Schmidt 2017).

Despite the high level of preparation, widely seen as overkill after the fact, I observed no frustration or sense of regret on the part of firefighters after the eclipse. When our engine arrived back at base that evening, there were a few conversations about how cool it was to experience the eclipse, but most of the talk was about the Lynx Fire.

\section{Discussion and Conclusion}

This paper has examined preparations by disaster managers for simultaneous hazards in August 2017: the hundreds of thousands of visitors expected with the total solar eclipse and the height of wildfire season. Despite, and because, of extensive preparation by managers in Central Oregon and around the state, worst-case scenarios largely did not materialize. Disaster managers developed plans based on uncertain predictions regarding hazards from the eclipse, while front-line workers responded to those plans with growing skepticism and a reliance on familiar risks.

Wildland firefighters are an ideal case for exploring, generally, how people respond to and prepare for uncertain future events, and, specifically, how a category of front-line workers 
respond to the uncertainties inherent in disaster preparation. Firefighters are accustomed to what looks like over-preparation: they exercise hard (almost) daily, they carry multiple liters of water and wear protective gear no matter the assignment, they have a "red bag"- a duffel for overnight or off-district fire assignments - packed and ready, and on most days the district has more engines and crews out patrolling than will actually respond to local fires. Thus, they are a population for whom preparation is a routine and expected part of the job.

Firefighters in the field showed confidence in plans based on accepted, familiar knowledge related to hazards and likelihood: they willingly discussed wildfire hazards and accepted the occurrence of the eclipse without question. Yet when it came to the impacts of a disaster event with which they had no prior familiarity, they showed general skepticism of plans made based on known unknowns or that hinted at the possibility of unknown unknowns. These front-line workers generally dismissed risks based on estimations or possibilistic thinking (Clarke 2006). They pushed back on plans to be stationed out in the field for eclipse week, identified hazards consistent with their regular jobs, and generally downplayed the severity of those hazards. This shows that those who are "boots on the ground" during disaster response recognize the limits of knowledge in disaster planning. It also suggests possible constraints on the all hazards approach that currently dominates emergency management in the United States, as disaster workers may be less comfortable veering outside of their training and prior experience to respond to different types of disaster events. This aligns with research on historical disasters identifying conflicts between those in positions of authority, on the one hand, and workers and the public, on the other (Remes 2017).

Applying a theoretically informed understanding of uncertainty and knowledge to this case offers improved insight into how and why disaster managers make decisions, and how those decisions are dynamically received by front-line disaster workers. My research demonstrates that front-line workers' responses to uncertainty is not merely a function of their position in a hierarchy, levels of discretion in their daily rounds, and how they interact with the public, key features of existing street-level bureaucracy research. Rather, it also reflects their evaluation of the knowledge that underpins the policies they are called to implement. In situations such as disaster preparedness and response where routinization and standardization are challenged by unknowns and uncertainty, front-line workers draw on the familiar to evaluate the unknown. In this case, firefighters evaluated the potential hazards associated with the solar eclipse through the lens of their daily rounds: driving and public interactions. Future research could explore whether this occurs in other cases: for example, how did front-line emergency medicine workers evaluate the hazards of COVID-19 early in the outbreak of the illness when uncertainties abounded, compared to months later when the arc of the pandemic was better understood?

Familiarity and extrapolation were also central to the development of plans by disaster managers, as they reached beyond local experience and occupation-specific risks. Uncomfortable with the idea that eclipse effects might include unknown unknowns, disaster managers developed extended knowledge (Gross 2007) based on prior events and experiences. Even though Central Oregon had not experienced a total eclipse in recent history, planners rejected the idea that the eclipse's hazards represented an area of non-knowledge or nescience. Instead, they identified known knowns and known unknowns related to the eclipse's impacts, drawing on eclipses elsewhere, other mass gathering events in Central Oregon, and creative thinking to identify and plan for worst-case scenarios. However, this worst-case planning was resisted by those charged with implementation, resistance that intensified as early predicted hazards associated with the eclipse, such as overwhelmed cell communications and inundated local 
businesses, failed to materialize. How different stakeholders respond to, minimize, deny, or accept uncertainty is central to how those stakeholders do their work, making sociological understanding of this phenomenon essential for disaster research moving forward.

As the prevalence and severity of disasters increases, more research is needed on how communities plan and prepare for simultaneous disaster and mass gathering events. Focusing on the preparedness phase of the disaster lifecycle for both the eclipse and the fire season, my ethnographic research was able to identify unexpected commonalities between these dissimilar hazards. Both involved preparing for worst-case scenarios which may not necessarily materialize, with significant implications for disaster management systems and for the allocation of resources. Both involved preparations that were hierarchical and top-down, with few opportunities for input and feedback from on-the-ground workers to in-the-office overhead. This has the potential to decrease buy-in from front-line workers, who may act with greater discretion in areas of their work that they see founded on uncertain information or unknowns. Just as crews were reluctant to camp at distant guard stations for the week of the eclipse, front-line responders may push back against other risk management policies (and the messages around those policies) perceived to be developed with little grounding in experiential knowledge or by office overhead staff who are not (or no longer) engaged in on-the-ground work.

These findings matter in a contemporary moment of widespread conspiracy theories and skepticism of public response to disasters (Merlan 2020). While skepticism of hierarchical power structures is central to many conspiracy theories (Hagen 2019), firefighters' pushback against disaster plans was instead a reaction to uncertainty, in particular a skepticism of predictions and management decisions based on non-knowledge and unknown hazards. Therefore, my research suggests that skepticism of disaster preparation and response may be particularly likely when significant uncertainty is associated with disaster hazards or likelihood. Understanding responses to disaster preparation is particularly urgent as the risks from wildfires, other hazards, and associated uncertainties are expected to increase with climate change and intensifying demographic vulnerabilities.

\section{Notes}

1 All names of individuals and specific places are pseudonyms.

2 The AHIMT that I shadowed in my research was most often deployed on wildland fires but had also been dispatched to a hurricane, terrorist attack, and complex criminal investigation.

3 An alternative definition defines the "event" as a medical incident such as a disease outbreak (WHO 2008, 7).

4 While wildland firefighters are not client-focused and often face fewer bureaucratic constraints in the performance of their daily routines than do other types of street-level bureaucrats, they do interact with the public regularly - particularly during events like the eclipse but also during routine parts of their job, such as patrolling for fires - and they have significant discretion in how they perform parts of their jobs.

5 This formulation draws on Kerwin's (1993) types of ignorance and Gross's (2007) classification of knowledge types. Additional categories discussed by Gross and Kerwin are worthy of future analysis but are generally beyond the scope of this analysis and thus do not appear in Table 1. 
6 While the typology of known knowns, unknown knowns, and unknown unknowns is often associated with former Secretary of State Donald Rumsfeld, these terms have a longer history in science and technology studies and climate science (Aven 2013; Kerwin 1993).

7 Some mass gathering events cannot be anticipated, such as spontaneous public protests.

8 Cascade National Forest, Cascade County, and Forestville are pseudonyms, as are names of all individuals.

9 Smokejumpers respond to wildfires by parachuting out of airplanes. Rappellers lower themselves out of helicopters on cables. Hotshots are members of handcrews with specialty training and certification. All three are considered to be elite wildland firefighters and are deployed to fires around the country, not just locally.

10 The experience of full-time firefighters employed by government agencies such as USFS or BLM is very different from that of contract crew firefighters, most of whom are on-call for extended periods of the fire season and work only when their crew is ordered to a specific fire (Pomeroy and Moseley 2007).

11 Overtime is expected by all involved. Supervisors expect firefighters to be willing to work overtime and up to 14 consecutive days to staff crews during peak season, and firefighters expect to receive significant overtime to counter their relatively low hourly wage. First-year firefighters (GS-3 pay scale) earn less than $\$ 12$ an hour following the federal pay scale, while an engine captain (GS-8) earns around \$20 an hour, for physically and mentally demanding and dangerous work.

12 This figure reflects the hierarchy I observed during my fieldwork. The hierarchy may take different forms in different agencies or regions.

13 I focus on eclipse preparations related to wildfire operations because that was the location of my fieldwork and because that offers the best lens for examining preparation and planning for simultaneous disaster events.

Acknowledgements I would like to express my deepest thanks to the firefighters, fire managers, and community leaders who shared their time and wisdom with me during my research, especially the leadership and crews of the Cascade National Forest fire management organization who welcomed me so generously. I am grateful to Janssie Zhu for helpful research assistance and Brian Mayer for valuable comments on an earlier draft of this paper. Lastly, many thanks to the anonymous Reviewers and Editor for helpful comments that have greatly improved this paper.

Funding No funding sources.

\section{References}

Bachelet, Dominique, James M. Lenihan, and Ronald P. Neilson. 2007. Wildfires and global climate change. Pew center on global climate change. https://www.fusee.org/documents/Wildfires_climate_change.pdf

Benight, Charles C. 2004. Collective efficacy following a series of natural disasters. Anxiety, Stress, and Coping. 17 (4): 401-420.

Brenkert-Smith, Hannah, Katherine L. Dickinson, Patricia A. Champ, and Nicholas Flores. 2013. Social amplification of wildfire risk: The role of social interactions and information sources. Risk Analysis. 33 (5): 800-817.

Brunsma, David, and J. Stephen Picou. 2008. Disasters in the twenty-first century: Modern destruction and future instruction. Social Forces. 87 (2): 983-991. 
Buckle, Philip. 2007. Preparedness, warning and evacuation. In Handbook of disaster research, $2^{\text {nd }}$ edition, eds. Havidán Rodríguez, E.L Quarantelli, and Russell R. Dynes, 493-504. New York: Springer.

Centers for Disease Control and Prevention. 2000. Public health aspects of the rainbow Family of living light annual gathering-Allegheny National Forest, Pennsylvania, 1999. Journal of the American Medical Association 283 (23): 3065-3066.

Cerulo, Karen. 2006. Never saw it coming: Cultural challenges to envisioning the worst. Chicago: University of Chicago Press.

Cherry, Katie E., Laura Sampson, Sandro Galea, Loren D. Marks, Pamela F. Nezat, Kayla H. Baudoin, and Bethany A. Lyon. 2017. Optimism and hope after multiple disasters: Relationships to health-related quality of life. Journal of Loss and Trauma. 22 (1): 61-76.

Clarke, Lee. 1989. Acceptable risk? Making decisions in a toxic environment. Berkeley: University of California Press.

Clarke, Lee. 2006. Worst cases: Terror and catastrophe in the popular imagination. Chicago: University of Chicago Press.

Cordner, Alissa. In press. Risk. In International handbook of environmental studies, eds. Beth Caniglia, David Pellow, Lori peek, Andrew Jorgenson, and Stephanie Malin. New York: Springer.

Desmond, Matthew. 2007. On the fireline: Living and dying with wildland firefighters. Chicago: University of Chicago Press.

Department of Homeland Security. 2017. National preparedness guidelines. Washington, DC: Department of Homeland Security.

Doan, Xuan Vihn, and Duncan Shaw. 2019. Resource allocation when planning for simultaneous disasters. European Journal of Operational Research. 274: 687-709.

Donner, William, and Walter Diaz. 2018. Methodological issues in disaster research. In Handbook of disaster research, 2nd edition, eds. Havidán Rodríguez, E.L Quarantelli, and Russell R. Dynes, 289-309. New York: Springer.

Eiser, J. Richard, Ann Bostrom, Ian Burton, David M. Johnston, John McClure, Douglas Paton, Joopvander Pligt, and Mathew P. White. 2012. Risk interpretation and action: A conceptual framework for responses to natural hazards. International Journal of Disaster Risk Reduction. 1: 5-16.

Emerson, Robert, Rachel Fretz, and Linda Shaw. 2011. Writing ethnographic fieldnotes. Chicago: Chicago: University of Chicago Press.

Freudenburg, William R. 1997. Contamination, corrosion, and the social order: An overview. Current Sociology. 45 (3): $19-40$.

Gill, Duane A., and Liesel A. Ritchie. 2018. Contributions of technological and natech disaster research to the social science disaster paradigm. Handbook of disaster research, 2nd edition, eds. Havidán Rodríguez, E.L Quarantelli, and Russell R. Dynes, 39-60. New York: Springer.

Gross, Matthias. 2007. The unknown in process: Dynamic connections of ignorance, non-knowledge and related concepts. Current Sociology. 55: 742-759.

Guevarra, Erica Cruz. 2017. Extreme heat reverses benefits of Oregon's above-average snowpack. OPB. August 8: 2017 https://www.opb.org/news/article/oregon-snowpack-heat-summer-2017/.

Hagen, Ryan. 2019. Collisions between institutional and populist risk imaginaries: The 'dark side' of negative asymmetrical thinking. Sociological Forum 34 (S1): 1235-1250.

Hamway, Stephen. 2017a. Rainbow Family, Forest Service disagree on festival impact. Associated Press, July 7.

Hamway, Stephen. 2017b. Brace for record crowds on public land for august eclipse. The Bend Bulletin (March $10)$.

International Association of Wildland Fire. 2013. WUI fact sheet. http://www.iawfonline.org/pdf/WUI_Fact Sheet_08012013.pdf. Accessed 25 Mar 2018.

Kerwin, Ann. 1993. "None too solid: Medical ignorance.” Knowledge: Creation, Diffusion. Utilization. 15(2): 166-185.

Lassa, Jonaten. 2016. Is there such a thing as a 'natural' disaster? RSIS Commentary. 279 (November): 1-3.

Luhmann, Niklas. 1995. Social systems. Stanford, CA: Stanford University Press.

Lyon, Bethany, Pamela Nezat, Katie Cherry, and Loren Marks. 2015. When multiple disasters strike: Louisiana fishers in the aftermath of hurricanes and the British petroleum Deepwater horizon oil spill. In Traumatic stress and long-term recovery: Coping with disasters and other negative life events, ed. Katie E. Cherry, 5770. New York: Springer.

Madsen, Peter. 2017. A look ahead at spring, summer outdoors. The Bend Bulletin (February 18).

Managi, Shunsuke, and Dabo Guan. 2017. Multiple disasters management: Lessons from the Fukushima triple events. Economic analysis and policy. 53: 114-122.

Marks, Loren D., Mandy Swanson, Olena Nesteruk, and Katrina Hopkins-Williams. 2006. Stressors in African American marriages and families: A qualitative study. Stress, trauma, and crisis: An international journal. 9: $203-225$. 
Matthewman, Steve. 2012. Accidentology: Towards a sociology of accidents and disasters. International and Multidisciplinary Journal of Social Sciences. 1 (2): 193-215.

McCaffrey, Sarah M., Eric Toman, Melanie Stidham, and Bruce Shindler. 2013. Social science research related to wildfire management: An overview of recent findings and future research needs. International Journal of Wildland Fire. 22: 15-24.

McCaffrey, Sarah. 2015. Community wildfire preparedness: A global state-of-the-knowledge summary of social science research. Current Forestry Reports. 1: 81-90.

McLaughlin, Kathleen. 2017. Demand for toilets could eclipse supply. The Bend Bulletin (May 7).

Meldrum, James R., Hannah Brenkert-Smith, Patricia A. Champ, Lilia Falk, Pamela Wilson, and Christopher M. Barth. 2018. Wildland urban interface residents' relationships with wildfire: Variation within and across communities. Society and Natural Resources. 31 (10): 1132-1148.

Merlan, Anna. 2020. Republic of lies: American conspiracy theorists and their surprising rise to power. London: Arrow Books.

Miller, Larry. 2012. All hazard incidents: Setting objectives and strategies. Fire Engineering. February: 75-79.

Mills, David, Russell Jones, Cameron Wobus, Julia Ekstrom, Lesley Jantarasami, Alexis St. Juliana, and Allison Crimmins. 2019. Projected age-stratified risk of exposure to inland flooding and wildfire smoke in the United States under two climate scenarios. Environmental Health Perspectives. 126 (4): 12.

Minciardi, Riccardo, Roberto Sacile, and Eva Transforini. 2009. Resource allocation in integrated preoperational and operational management of natural hazards. Risk Analysis. 29 (1): 62-75.

Mora, Camilo, Daniele Spirandelli, Erik C. Franklin, John Lynham, Michael B. Kantar, Wendy Miles, Charlotte Z. Smith, Kelle Freel, Jade Moy, Leo V. Louis, Evan W. Barba, Keith Bettinger, Abby G. Frazier, John F. Colburn IX, Naota Hanasaki, Ed Hawkins, Yukiko Hirabayashi, Wolfgang Knorr, Christopher M. Little, Kerry Emanuel, Justin Sheffield, Jonathan A. Patz, and Cynthia L. Hunter. 2018. Broad threat to humanity from cumulative climate hazards intensified by greenhouse gas emissions. Nature Climate Change. 8:10621071.

Moseley, Michael E. 1999. Convergent catastrophe: Past patterns and future implications of collateral natural disasters in the Andes. In The angry earth: Disaster in anthropological perspective, eds. Antony OliverSmith and Susanna M. Hoffman, 59-71. New York: Routledge.

National Aeronautics and Space Administration. 2017a. Eclipse: 101 https://eclipse2017.nasa.gov/faq. Accessed 15 Aug 2019.

NASA. 2017b. Total Solar Eclipse over Madras, Oregon. https://www.nasa.gov/image-feature/total-solareclipse-over-madras-oregon. Accessed 15 Aug 2019.

National Incident Management System. 2019. https:/training.fema.gov/nims/. Accessed 15 Aug 2019.

National Interagency Fire Center. 2019. Statistics. https://www.nifc.gov/fireInfo/fireInfo_statistics.html. Accessed 29 May 2019.

National Research Council. 1991. A safer future: Reducing the impacts of natural disasters. Washington, DC: The National Academies Press.

National Research Council. 2012. Disaster resilience: A national imperative. Washington, DC: The National Academies Press.

National Resources Conservation Service. 2017. Oregon basin outlook report. May 1: 2017 https://www.wcc. nrcs.usda.gov/ftpref/states/or/watersupply/2017/WSOR_2017_May.pdf. Accessed 15 Aug 2019.

National Weather Service. 2020. NOAA technical memorandum NWS SR-145. https://www.weather. gov/oun/spotterglossary. Accessed 23 Mar 2020.

Neale, Timothy, and Jessica K. Weir. 2015. Navigating scientific uncertainty in wildfire and flood risk mitigation: A qualitative review. International journal of disaster risk reduction. 13: 255-265.

National Wildfire Coordinating Group. 2020. 6 minutes for safety. https:/www.nwcg.gov/committees/6Minutes-for-safety. Accessed 19 Mar 2020.

Paté-Cornell, Elisabeth. 1990. Organizational aspects of engineering system safety: The case of offshore platforms. Science. 250 (4985): 1210-1217.

Paté-Cornell, Elisabeth. 2012. On "black swans" and "perfect storms": Risk analysis and management when statistics are not enough. Risk Analysis. 32 (11): 1823-1833.

Paveglio, Travis B., Todd Norton, and Matthew S. Carroll. 2011. Fanning the flames? Media coverage during wildfire events and its relation to broader societal understandings of the hazard. Human Ecology Review. 18 (1): 41-52.

Perrow, Charles. 1984. Normal accidents. New York: Basic Books.

Perry, Ronald W. 2018. Defining disaster: An evolving concept. In Handbook of disaster research, 2nd edition, eds. Havidán Rodríguez, E.L Quarantelli, and Russell R. Dynes, 3-22. New York: Springer.

Pillai, Parvathy, Aimee Palumbo, Jennifer Quammen, Dennis P. Fabore, Perrianne Lurie, Atmaram Nambiar, Judi Sedivy, Virginia Dato, Enzo Campagnolo, Andre Weltman, and Maria Moll. 2011. Public health 
surveillance at the rainbow Family annual gathering - Pennsylvania, 2010. Pennsylvania Epi Notes. 1 (1): 4 7.

Pomeroy, Alaina, and Cassandra Moseley. 2007. Contract and federal wildland firefighters: A review of local opportunity, job quality, and safety. Ecosystem Workforce Program. Eugene, OR: University of Oregon.

Portillo, Shannon, and Danielle S. Rudes. 2014. Construction of justice at the street level. Annual Review of Law and Social Science. 10: 321-334.

Ragin, Charles C., and Lisa M. Amoroso. 2019. Constructing social research: The unity and diversity of method. Los Angeles: Sage.

Rainbow Family. 2018. Homepage. https://www.welcomehome.org/. Accessed 15 Aug 2019.

Ray-Bennett, Nibedita S. 2009. Multiple disasters and policy responses in pre- and post-independence Orissa, India. Disasters. 33 (2): 274-290.

Remes, Jacob A.C. 2017. Disaster citizenship: Survivors, solidarity, and power in the progressive era. Urbana: University of Illinois Press.

Schmidt, Brad. 2017. Eclipse 2017: Did Oregon really welcome 1 million visitors? The Oregonian, August 22.

Scruggs, Greg. 2017. I watched the eclipse with 70,000 hippies on an Oregon prairie. The Stranger, August 22.

Soomaroo, Lee, and Virginia Murray. 2012. Disasters at mass gatherings: Lessons from history. PLoS Currents 4. https://doi.org/10.1371/currents.RRN1301.

Spurr, Kyle. 2017. Eclipse traffic already backing up in Central Oregon. The Bend Bulletin (August 16).

Tierney, Kathleen. 2007. From the margins to the mainstream? Disaster research at the crossroads. Annual Review of Sociology. 33: 503-525.

Tierney, Kathleen. 2019. Disasters: A sociological approach. Cambridge: Polity.

Time and Date. 2019. Find solar \& lunar eclipses in your city. https://www.timeanddate.com/eclipse/. Accessed 8 Aug 2019.

Vaughan, Dianne. 1996. The challenger launch decision. Chicago: University of Chicago Press.

Vaughan, Dianne. 1999. The dark side of organizations: Mistake, misconduct, and disaster. Annual Review of Sociology. 25: 271-305.

Wisner, Ben, Piers Blaikie, Terry Cannon, and Ian Davis. 2004. At risk: Natural hazards, people's vulnerability and disasters. London: Routledge.

World Health Organization. 2008. Communicable disease alert and response for mass gatherings: Key considerations. Geneva: World Health Organization https://www.who.int/csr/Mass gatherings2.pdf?ua=1.

Zinn, Jens O. 2008. Introduction: The contribution of sociology to the discourse on risk and uncertainty. In Social theories of risk and uncertainty: An introduction, ed. Jens Zinn, 1-17. Malden, MA: Blackwell Publishing.

Publisher's Note Springer Nature remains neutral with regard to jurisdictional claims in published maps and institutional affiliations.

Alissa Cordner is Associate Professor and Paul Garrett Fellow at Whitman College, where she teaches sociology and environmental studies courses. Her research focuses on environmental sociology, the sociology of risk and disasters, environmental health and justice, and public engagement in science and policy making. She is the author of Toxic Safety: Flame Retardants, Chemical Controversies, and Environmental Health (2016, Columbia University Press) and the co-author of The Civic Imagination: Making a Difference in American Political Life (2014, Paradigm Publishers). 